\title{
Assessment of Meat Quality and Shelf Life from Broilers Fed with Different Sources and Concentrations of Methionine
}

\author{
Antonia Albrecht $\mathbb{D D}^{1}{ }^{1}$ Martin Hebel, ${ }^{1}$ Céline Heinemann $\left(\mathbb{D},{ }^{1}\right.$ Ulrike Herbert $\left(\mathbb{D},{ }^{1}\right.$ \\ Dennis Miskel, ${ }^{1}$ Behnam Saremi, ${ }^{2}$ and Judith Kreyenschmidt $\left(\mathbb{D}^{1}\right.$ \\ ${ }^{1}$ Institute of Animal Science, University of Bonn, Katzenburgweg 7-9, 53115 Bonn, Germany \\ ${ }^{2}$ Evonik Nutrition \& Care GmbH, Rodenbacher Chaussee 4, 63457 Hanau-Wolfgang, Germany \\ Correspondence should be addressed to Antonia Albrecht; a_albrecht@uni-bonn.de
}

Received 22 November 2018; Accepted 28 January 2019; Published 26 February 2019

Academic Editor: Jordi Rovira

Copyright ( 2019 Antonia Albrecht et al. This is an open access article distributed under the Creative Commons Attribution License, which permits unrestricted use, distribution, and reproduction in any medium, provided the original work is properly cited.

\begin{abstract}
A trial with different concentrations of DL-methionine (DLM) and DL-2-hydroxy-4-methylthiobutanoic acid (DL-HMTBA) in broiler feed was performed to investigate their effect on the meat quality parameters and the shelf life of breast fillet. In total, fillets from 210 male broiler chickens (Ross 308) were tested in seven groups with 30 animals each. Three different concentrations (0.04, 0.12 , and $0.32 \%$; on an equimolar basis) of either DLM or DL-HMTBA were added to a basal diet, summing up to seven treatment groups. After slaughter, fillets were packed aerobically and stored at $4^{\circ} \mathrm{C}$. The investigated parameters comprised measurements of microbial as well as physicochemical parameters, such as $\mathrm{pH}$, drip loss, cooking loss, and color measurements. Additionally, sensory investigations were conducted and shelf life was calculated. Mean pH values were between 6.1 and 6.4. Drip loss values were low, with mean values below $0.4 \%$. The cooking loss ranged between $22 \%$ and $28 \%$ on average. The fillets showed a normal initial microbial quality $\left(2.5 \log _{10} \mathrm{cfu} / \mathrm{g}\right)$ and spoilage process with microbial counts of $8.5 \log _{10} \mathrm{cfu} / \mathrm{g}$ at the end of storage. The study revealed a significant influence of methionine supplementation on the quality of broiler breast meat in comparison with the basal group. Methionine supplementation led to higher $\mathrm{pH}$ values and a higher water binding. Higher concentrations of methionine had a positive influence on the water-holding capacity by lowering the cooking loss. The $L^{*}$ value showed a significant negative correlation to the methionine concentration supplemented. No differences in physicochemical as well as sensory parameters could be detected between both methionine sources. The fillets showed a normal sensory spoilage process and a shelf life of $6 \mathrm{~d}$. White striping was positively correlated to fillet weight as well as color values and significantly affected the Purchase Decision, the sensory investigation, and thus the shelf life of the samples.
\end{abstract}

\section{Introduction}

As the first limiting amino acid in grain and soybean meal diets, methionine (Met) is widely used as a supplement in broiler feed in poultry production $[1,2]$. Two common synthetic Met sources are DL-methionine (DLM) and DLmethionine hydroxy analogue free acid (DL-HMTBA). Positive effects of both Met sources on weight gain are undisputed $[3,4]$, but differences in the bioavailability and efficacy have been discussed in several studies [5-13]. The different structure of both molecules results in diverging absorption, metabolic pathways, and physiologic transformation [14, 15].
Besides the positive effect of Met on the growth and feed conversion rate of the animals, Met supplementation is known to increase the breast and leg meat yield of broilers, irrespective of the Met source used [16-20]. Additionally, the abdominal fat content is reduced $[3,11,18]$ as well as the absolute fat content in the fillet [21]. The influence of Met supplementation on lipogenesis is discussed as a potential support to producing lean poultry meat $[22,23]$. However, positive effects on the nutritional value of poultry meat remain controversial, since Liu et al. [18] reported no effect on the absolute content of fat or crude protein. In several studies, it was shown that Met supplementation has the ability to influence important quality 
parameters of the meat. Increasing Met concentrations in the diet elevates the $\mathrm{pH}$ of broiler meat $[21,24]$. The meat color is affected by lowering the $L^{*}$ and $b^{*}$ value [21]. Hence, the coloration of fillets and thighs is judged superior in comparison to Met-deficient diets [18]. These intrinsic characteristics, such as the structure, nutrient content, $\mathrm{pH}$, or water availability, have a large impact on the spoilage process of the meat $[25,26]$, especially poultry meat [27]. Generally, changes in the physicochemical properties of poultry meat might lead to differences in the microbial spoilage process. Indeed, a relationship between Met supplementation and bacterial counts on the meat surface has been reported, but the results are contradictory. While Aksu et al. [21] detected lowering bacterial counts with increasing dietary Met concentrations, Albrecht et al. [24] found a supporting effect on microbial growth. In fact, there is a lack of studies focusing on the relationship between the microbial growth and the shelf life of the meat and Met supplementation. In addition to the effect on the physicochemical properties of meat, the lipid oxidation during storage can be decreased by the increase of supplemental Met [28]. The diets supplemented with Met are reported to have a positive effect on lipid oxidation of the investigated broiler fillets [21, 23, 29]. Lipid oxidation is a major factor during the spoilage of fresh meat and influences consumer acceptance of the product [30]. Furthermore, a positive effect on the sensory acceptance in comparison to the control group was reported by Albrecht et al. [24]. However, it became evident during the laboratory trial that a large number of samples expressed white striping (WS), a breast myopathy. WS is reported to be especially frequent in heavier fillets [31-33]. Genetic selection with a focus on fast production, high growth rates, and enlarged meat yield is supposed to increase the potential for meat defects such as WS and wooden breast [31, 34-37]. Meat quality parameters are affected by Met supplementation. But up to now, there is a lack of studies describing the relationship between breast myopathies and typical spoilage parameters as well as shelf life. Additionally, the ability of Met supplementation to increase growth rates and meat yield of broiler and a possible influence on the prevalence on WS has not been investigated yet. Up to now, there are hardly any published studies focusing on the correlation between dietary Met supplementation and physicochemical parameters, like microbial load, breast myopathies and typical sensory parameters of commercially produced broiler meat. Thus, the objective of this study was to investigate the effect of different concentrations of liquid DL-2-hydroxy4-methylthiobutanoic acid (DL-HMTBA) relative to DLmethionine (DLM) in chicken feed on the meat quality parameters, meat defects, spoilage process, and shelf life of commercially produced breast fillets.

\section{Materials and Methods}

2.1. Study Design. Upon hatching, 800 male broiler chickens (Ross 308) with a weight of $42 \mathrm{~g}$ were allocated to six treatments and one basal group as control. All treatments were replicated six times with 20 birds per replication each, except for both highest Met concentrations. The highest concentrations for DLM and DL-HMTBA were replicated five times with 20 birds each. Raising and feeding was conducted at the facilities of the company feedtest (WettinLöbejün, Germany). The treatment groups comprised three concentrations of each Met source: DLM (MetAMINO, Evonik Nutrition \& Care GmbH, Germany) and DLHMTBA (MHA, Novus Europe SA/NV, Brussels, Belgium). The concentrations supplemented at $0.04 \%, 0.12 \%$, or $0.32 \%$ of either DLM or DL-HMTBA on an equimolar base to a control basal diet (Table 1) deficient in Met + Cys.

The slaughter and butchering of the broiler took place at the age of $35 \mathrm{~d}$. For each treatment, 30 birds were randomly selected. The slaughtering and cooling process was conducted in a commercial slaughterhouse in Jena (Gönnataler Putenspezialitäten $\mathrm{GmbH}$, Germany) to simulate practical conditions. Thus, influences of a deficient cooling and processing procedure could be minimized.

The samples were transported to the University of Bonn under temperature-controlled conditions in insulated boxes with cooling packs. The fillets were individually placed in polypropylene trays with lids and were stored at $4^{\circ} \mathrm{C}$ in lowtemperature high-precision incubators (Sanyo model MIR 153, Sanyo Electric Co., Ora-Gun, Gumma, Japan). The storage temperature was monitored by data loggers (ESCORT JUNIOR Internal Temperature Data Logger, Escort, New Zealand) every 3 minutes. Laboratory investigations started $24 \mathrm{~h}$ postmortem and comprised weighing of the fillets, measurements of physicochemical parameters $(\mathrm{pH}$, drip loss, and cooking loss), and microbial investigations. This investigation block was repeated at $192 \mathrm{~h}$ of storage. Color measurements were conducted after $24 \mathrm{~h}, 168 \mathrm{~h}$, and 216 h. Sensory investigations, including Purchase Decision and breast myopathies like WS, covered the whole storage period with six investigation points at intervals of $24 \mathrm{~h}$ to $48 \mathrm{~h}$.

\subsection{Physicochemical Analysis}

2.2.1. Measurement of the Meat $p H$ Value. The surface $\mathrm{pH}$ of the fillets was measured using two portable surface $\mathrm{pH}$ meters ( $\mathrm{pH}$ 8011, Peter Bock Umwelttechnik, Gersfeld, Germany; GPH114, GHM Messtechnik GmbH Standort Greisinger, Regenstauf, Germany). Two measurements were performed for each meat sample by placing the electrode onto the meat surface and an average $\mathrm{pH}$ value was calculated.

2.2.2. Measurement of the Drip Loss. The measurement of drip loss and cooking loss was conducted to characterize the water-binding capacity of the meat samples [38]. Drip loss measurements of the breast fillets were conducted after $24 \mathrm{~h}$ and $192 \mathrm{~h}$ of storage. After being packed in plastic bags, meat samples were hung on hooks through their thickest part for $24 \mathrm{~h}$ in a $4^{\circ} \mathrm{C}$ incubator. Samples were weighed before and after hanging. Drip loss was calculated as the loss in weight, corrected for size, and expressed as a percent.

$$
D_{\mathrm{L}}=\frac{m_{1}-m_{2}}{m_{1}} \cdot 100 \%
$$


TABle 1: Feeding composition of the basal diet.

\begin{tabular}{lccc}
\hline & $0-10 \mathrm{~d}$ & $11-22 \mathrm{~d}$ & $23-35 \mathrm{~d}$ \\
\hline Diet composition & & & \\
Corn (\%) & 46.3 & 58.63 & 58.67 \\
Soybean meal, 48\% CP & 26.81 & 24.80 & 20.89 \\
Peas (\%) & 10.00 & 5.19 & 10.00 \\
Corn gluten meal, 60\% CP (\%) & 8.87 & 3.66 & 2.40 \\
Soybean oil (\%) & 3.09 & 3.31 & 4.24 \\
Monocalcium phosphate (\%) & 1.71 & 1.54 & 1.23 \\
Limestone (CaCO $)(\%)$ & 1.64 & 1.35 & 4.24 \\
Premix blank poultry (\%) & 0.50 & 0.50 & 0.50 \\
L-Lysine (\%) & 0.37 & 0.28 & 0.23 \\
Sodium bicarbonate (\%) & 0.24 & 0.22 & 0.00 \\
Salt (NaCl) (\%) & 0.18 & 0.21 & 0.35 \\
Choline chloride, 60\% & 0.15 & 0.13 & 0.15 \\
ThreAMINO ${ }^{\circledR}$ & 0.08 & 0.09 & 0.08 \\
ValAMINO (L-valine) & 0.05 & 0.07 & 0.07 \\
L-Isoleucine & 0.00 & 0.00 & 0.03 \\
Nutrient composition (\%) & & & \\
Crude protein & 24.26 & 20.00 & 18.15 \\
AMEn (MJ/kg) & 12.70 & 12.97 & 13.31 \\
AMEn (kcal/kg) & 3.035 & 3.100 & 3.180 \\
SID Lys & 1.29 & 1.10 & 1.00 \\
SID Met & 0.34 & 0.27 & 0.24 \\
SID Cys & 0.30 & 0.26 & 0.23 \\
SID M + C & 0.64 & 0.53 & 0.47 \\
SID Thr & 0.82 & 0.71 & 0.65 \\
SID Trp & 0.21 & 0.18 & 0.16 \\
SID Arg & 1.32 & 1.14 & 1.05 \\
SID Ile & 0.91 & 0.76 & 0.71 \\
SID Leu & 2.17 & 1.67 & 1.47 \\
SID Val & 1.02 & 0.88 & 0.80 \\
\hline
\end{tabular}

where $D_{\mathrm{L}}$ is the drip loss (\%), $m_{1}$ is mass before hanging, and $m_{2}$ is mass after hanging.

2.2.3. Measurement of the Cooking Loss. Measurements of the cooking loss were performed $24 \mathrm{~h}$ after slaughter. A sample of around $3 \times 5 \mathrm{~cm}$ was taken with a scalpel from the caudal end of the fillets. The samples were weighed and packed separately in autoclave bags. The samples were cooked at $80^{\circ} \mathrm{C}$ in a water bath (Memmert, Schwabach, Germany) until the core temperature of the fillets reached $72^{\circ} \mathrm{C}$. The core temperature was measured with a food core thermometer (Testo, Lenzkirch, Germany). A second weighing was conducted after cooking, and the cooking loss was calculated as the loss in weight, corrected for size, and expressed as a percent (equation (1)).

2.2.4. Color Measurements. Color measurements were conducted at $24 \mathrm{~h}, 168 \mathrm{~h}$, and $216 \mathrm{~h}$ of storage with a large view spectrophotometer (MiniScan EZ 4500L, HunterLab, Murnau). The device works with a wavelength between $400 \mathrm{~nm}$ and $700 \mathrm{~nm}$ and a $45^{\circ} / 0^{\circ}$ geometry. The CIE 1976 $L^{*} a^{*} b^{*}$ scale was used, measured with D65 illuminant (6500 K daylight). The fillets were placed on cooled glass plates for the measurements. The $L^{*} a^{*} b^{*}$ and $C^{*}, h^{\circ}$ values were recorded for each fillet at three sample points to get a representative evaluation of the samples. Only the $L^{*} a^{*} b^{*}$ values were selected for analysis and measurements were averaged for each fillet.

2.3. Microbiological Analysis. For the microbiological analysis, $25 \mathrm{~g}$ of surface meat tissue, with a size of $3.5 \times 7 \times 0.5 \mathrm{~cm}$, was aseptically taken using a sterile scalpel. The sample was transferred to a filtered, sterile stomacher bag and filled with $225 \mathrm{ml}$ of saline peptone diluent $(0.85 \%$ $\mathrm{NaCl}$ with $0.1 \%$ peptone Saline-Tablets, Oxoid BR0053G, Cambridge, United Kingdom). The samples were mixed with a Stomacher 400 (Kleinfeld Labortechnik, Gehrden, Germany) for $60 \mathrm{~s}$. Tenfold dilutions of the homogenate were prepared in saline peptone diluents. Pseudomonas spp. (PSE) were detected by spread plate technique on Pseudomonas agar with cetrimide-fucidin-cephalosporine-selective supplement (CFC, Oxoid, Cambridge, United Kingdom). Plates were incubated at $25^{\circ} \mathrm{C}$ for 48 hours.

2.4. Sensory Investigations. Sensory investigations comprised the sensory evaluation of the spoilage process to determine the shelf life of the samples, an assessment of meat failures such as WS and the Purchase Decision. All sensory investigations were performed by a trained sensory panel including six panelists after $24 \mathrm{~h}, 72 \mathrm{~h}, 120 \mathrm{~h}, 168 \mathrm{~h}, 192 \mathrm{~h}$, and $216 \mathrm{~h}$. The training of panelists was conducted during former trials and exercise courses prior to the main trial.

2.4.1. Purchase Decision. Before each sensory evaluation, the sensory panel evaluated the samples for the trait Purchase Decision. Based on overall visual appearance, each panelist chose whether they would purchase each sample or not. In order to avoid biased perceptions of the samples (i.e., through odor), this answer was given prior to the other sensory evaluations. The results of all panelists were then averaged for each sample.

Additionally, the sensory panel noted demerits visually apparent on the meat surface such as hematoma, cuts caused by processing failures or color anomalies. Demerits went into the analysis as total number for every fillet.

2.4.2. Sensory Index. For each sample, the characteristics such as color, odor, and texture were assessed via a graded three-point-scoring system, with three meaning fresh and high quality and one meaning unacceptable. The Sensory Index (SI) was calculated as a weighted average with the following equation:

$$
\mathrm{SI}=\frac{2 \cdot O+2 \cdot C+T}{5},
$$

where SI is the Sensory Index, $O$ the is the odor, $C$ is the color, and $T$ is the texture.

According to the scheme, the product is spoiled when the SI reaches the level of 1.8. The SI was plotted as a function of time and fitted to a linear model. Thus, the shelf life of each sample was calculated as follows [39]: 


$$
\mathrm{SL}=\frac{1.8-a}{b},
$$

where SL is the shelf life, $a$ is the intercept of the linear model, and $b$ is the slope of the linear model.

2.4.3. Assessment of White Striping. Following the sensory evaluation, the appearance of WS was evaluated by the sensory panel with a 3-point scoring system. A score of "0" means no WS, "1" means medium WS, and "2" means severe WS (Figure 1). The results of all panelists were then averaged for each sample.

2.5. Data Analysis and Statistics. Data were tested for normal distribution and homoscedasticity. Since data did not meet the conditions for parametric statistical tests, nonparametric methods for statistical tests were used. For illustrating data distribution, boxplots were used displaying median as well as first and third quartiles of data. Differences between groups were tested with the Kruskal-Wallis test. In the event of significant differences, pairwise comparisons were performed with the Dunn-Bonferroni test to test differences between individual groups. Correlations were tested with Spearman's rank correlation test and the correlation coefficient $k$ was computed (with $k<0.4$ meaning a low correlation, $0.4<k<0.6$ meaning a medium correlation and $k>0.6$ meaning a high correlation). Test results are marked with ${ }^{*}(p<0.05)$ for significant and ${ }^{* *}(p<0.001)$ for highly significant differences or correlations.

To explore the influence of several explanatory variables on the response variable "Purchase Decision," a multiple linear model was calculated. Predictors with a significant influence on the response variable were used to calculate and plot a second-degree response surface model.

Data analysis was conducted with statistical software $\mathrm{R}$ 2.15 (R Development Core Team). Additionally, SPSS Statistics 23 (IBM Corp. 1989, 2013, New York, USA) and OriginPro 8G (OriginLab Corp., Northampton, MA, USA) were used.

\section{Results and Discussion}

The investigated samples had fillet weights between $47.2 \mathrm{~g}$ and $288.75 \mathrm{~g}$ with mean values between $83.17 \mathrm{~g}$ and $240.20 \mathrm{~g}$ (Table 2 ). The fillet weight was significantly correlated to the Met concentration $(k: 0.914 ; p<0.001$, Table 3$)$. The difference in weight gain between concentration groups was significant $(p<0.001)$. The results of this study are in accordance with former studies reporting a significant increase of breast meat yield in Met-supplemented broilers $[8,16-20]$.

The $\mathrm{pH}$ value of the fillets ranged between 6.20 and 6.35 at the first investigation point (Table 2). For poultry fillets, the typical range of $\mathrm{pH}$ values $24 \mathrm{~h}$ after slaughter is between 5.6 and $5.9[40,41]$ but may also range up to 6.02 [27]. A storage-related increase of meat $\mathrm{pH}$ up to values between 6.43 and 6.58 was observed and can be explained by an accumulation of metabolites of the growing microorganisms
[42]. The basal group showed significantly lower $\mathrm{pH}$ values at the beginning of storage $(p<0.05)$, indicating that Met supplementation elevates the ultimate meat $\mathrm{pH}$ as reported in former studies [21, 24]. The positive effect of Met supplementation on stress-related genes and protective cellular mechanisms against oxidative stress might explain higher $\mathrm{pH}$ values [43-45]. Meat $\mathrm{pH}$ is strongly influenced by stress during the preslaughter and slaughter processes, meaning that high stress leads to an accumulation of lactic acid in the muscle, resulting in a lower ultimate meat $\mathrm{pH}[41,46]$. Thus, the comparatively high $\mathrm{pH}$ values during this trial are possibly caused by an enhanced metabolic stress resistance by Met supplementation, whereas no significant difference was observed between Met sources $(p>0.05)$. The absence of lactic acid in muscle tissue, leading to a higher meat $\mathrm{pH}$, is associated with a high water-binding capacity of the myofibrillar proteins [47].

The drip loss of the breast fillets ranged between $0.18 \%$ and $0.40 \% 24 \mathrm{~h}$ after slaughter (Table 2). The basal group had a significantly higher drip loss than both the DLM 0.12 and $0.32(p=0.03)$ and the DL-HMTBA 0.32 groups ( $p=0.035)$, but there was no difference between Met sources $(p>0.05)$. In general, drip loss values were lower in comparison to other studies with mean drip loss values between $0.42 \%$ and $3.32 \%$ [48-50]. Additionally, the supplementation of Met showed a tendency to lower the drip loss of the breast fillets, which was confirmed by a significant but low negative correlation between Met concentration and drip loss $24 \mathrm{~h}$ after slaughter $(k:-0.205 ; p=0.003)$. This contradicts findings of former studies reporting a positive relationship between increasing Met concentrations and drip loss or moisture content $[18,24]$. Reduced drip loss values in comparison to the basal group are in accordance with the effects of Met supplementation on elevated meat $\mathrm{pH}$ and former studies, which reported lowering drip loss values with increasing Met concentration [29]. However, differences in drip loss between all groups seem to fade during storage. After $192 \mathrm{~h}$, drip loss showed a slight increase to mean values between $0.23 \%$ and $0.30 \%$ (Table 6 , Supplementary materials) and a convergence between the groups, which is probably caused by the spoilage process and the enzymatic and chemical deterioration of the meat. Drip loss values at $192 \mathrm{~h}$ showed no differences $(p>0.05)$ between treatment groups and no significant correlations to the Met concentration.

The mean cooking loss of the breast fillets varied between $22 \%$ and $28 \%$, and no significant difference between the Met sources was observed (Table 2). The cooking loss of the $0.32 \%$ Met supplementation was significantly lower than both the basal group $(p=0.004)$ and the $0.04 \%$ Met supplementation $(p=0.022)$. The cooking loss was negatively correlated to the Met concentration, irrespective of the treatment groups $(k=-0.377 ; p<0.001)$. In general, the water-binding capacity of meat is influenced by the genotype, a fast muscle growth, preslaughter stress as well as the conditions during slaughter and processing [41, 47]. An influence of the diet composition on the water-holding capacity of meat has been reported [51-54]. Met supplementation seems to improve the water-binding 


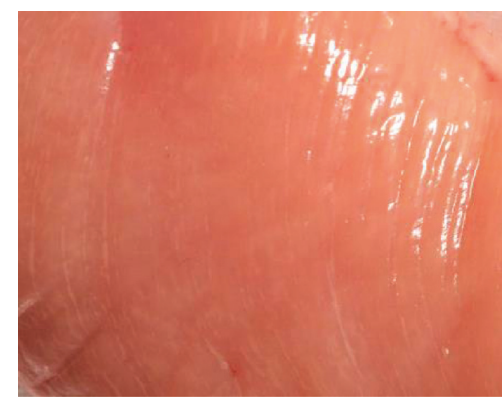

(a)

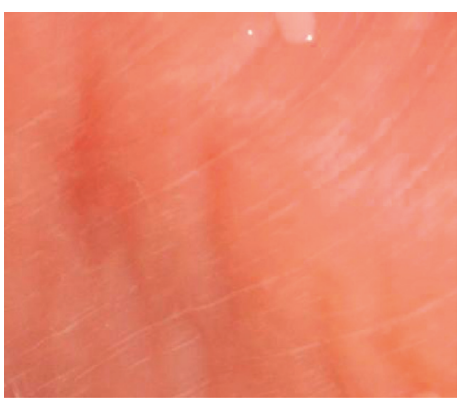

(b)

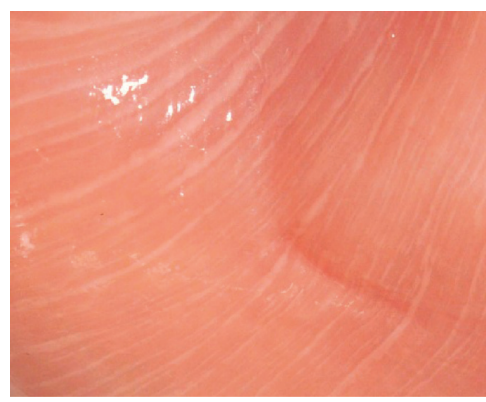

(c)

Figure 1: White striping: 0-no WS (a), 1-medium WS (b), and 2-severe WS (c).

TAвLE 2: Meat quality parameters in breast muscle of chickens fed based on different Met sources and concentrations.

\begin{tabular}{|c|c|c|c|c|c|c|c|}
\hline & Basal & DLM 0.04 & DLM 0.12 & DLM 0.32 & $\begin{array}{c}\text { DL-HMTBA } \\
0.04\end{array}$ & $\begin{array}{c}\text { DL-HMTBA } \\
0.12\end{array}$ & $\begin{array}{c}\text { DL-HMTBA } \\
0.32\end{array}$ \\
\hline Weight & $83.17^{a} \pm 17.53$ & $148.80^{\mathrm{bc}} \pm 20.37$ & $205.25^{\text {def }} \pm 25.37$ & $240.20^{\mathrm{dg}} \pm 20.79$ & $134.95^{\mathrm{ab}} \pm 20.48$ & $183.27^{\mathrm{ce}} \pm 22.30$ & $233.37^{\mathrm{fg}} \pm 24.64$ \\
\hline $\mathrm{Pse}_{24}(\mathrm{cfu} / \mathrm{g})$ & $2.07^{\mathrm{a}} \pm 1.00$ & $1.61^{\mathrm{a}} \pm 0.55$ & $1.79^{\mathrm{a}} \pm 0.51$ & $2.08^{\mathrm{a}} \pm 0.89$ & $1.67^{a} \pm 0.66$ & $2.17^{\mathrm{a}} \pm 0.59$ & $1.72^{\mathrm{a}} \pm 0.65$ \\
\hline $\begin{array}{l}\text { Pse }_{192} \text { (cfu/ } \\
\text { g) }\end{array}$ & $8.29^{a} \pm 0.52$ & $8.51^{b} \pm 0.44$ & $8.17^{\mathrm{a}} \pm 0.39$ & $7.82^{\mathrm{ab}} \pm 0.53$ & $8.08^{\mathrm{a}} \pm 0.43$ & $7.89^{\mathrm{ab}} \pm 0.41$ & $7.96^{\mathrm{a}} \pm 0.48$ \\
\hline $\mathrm{pH}_{24}$ & $6.16^{\mathrm{a}} \pm 0.17$ & $6.30^{b} \pm 0.15$ & $6.30^{b} \pm 0.15$ & $6.27^{\mathrm{b}} \pm 0.19$ & $6.23^{\mathrm{ab}} \pm 0.21$ & $6.28^{b} \pm 0.22$ & $6.32^{b} \pm 0.18$ \\
\hline $\mathrm{DL}_{24}$ & $0.402^{\mathrm{a}} \pm 0.34$ & $0.217^{\mathrm{ab}} \pm 0.12$ & $0.175^{\mathrm{b}} \pm 0.10$ & $0.216^{\mathrm{b}} \pm 0.20$ & $0.295^{\mathrm{ab}} \pm 0.27$ & $0.213^{\mathrm{ab}} \pm 0.10$ & $0.192^{\mathrm{b}} \pm 0.17$ \\
\hline $\mathrm{CL}$ & $28.21^{\mathrm{a}} \pm 7.56$ & $25.86^{\mathrm{ab}} \pm 6.43$ & $22.97^{\mathrm{ab}} \pm 5.16$ & $22.24^{\mathrm{ab}} \pm 5.61$ & $26.90^{\mathrm{ab}} \pm 6.26$ & $24.53^{\mathrm{ab}} \pm 5.14$ & $22.13^{\mathrm{b}} \pm 4.91$ \\
\hline$L_{24}^{*}$ & $57.61^{\mathrm{ab}} \pm 2.14$ & $58.80^{\mathrm{a}} \pm 2.55$ & $57.21^{\mathrm{ab}} \pm 2.94$ & $55.68^{b} \pm 2.67$ & $58.14^{\mathrm{a}} \pm 2.57$ & $58.33^{\mathrm{a}} \pm 2.59$ & $56.60^{\mathrm{ab}} \pm 3.2$ \\
\hline$a_{24}^{* 4}$ & $7.2^{\mathrm{a}} \pm 0.95$ & $6.88^{\mathrm{ab}} \pm 0.91$ & $6.8^{\mathrm{ab}} \pm 1.08$ & $6.61^{\mathrm{ab}} \pm 1.08$ & $7.03^{\mathrm{ab}} \pm 1.09$ & $6.62^{\mathrm{ab}} \pm 0.89$ & $6.32^{b} \pm 0.73$ \\
\hline$b_{24}^{* 4}$ & $14.93^{\mathrm{a}} \pm 1.18$ & $15.88^{\mathrm{ab}} \pm 1.31$ & $15.65^{\mathrm{ab}} \pm 1.57$ & $14.87^{\mathrm{ab}} \pm 1.76$ & $15.8^{\mathrm{ab}} \pm 1.82$ & $15.72^{\mathrm{ab}} \pm 1.72$ & $15.14^{\mathrm{b}} \pm 1.61$ \\
\hline $\mathrm{SI}_{24}^{24}$ & $2.79^{\mathrm{a}} \pm 0.07$ & $2.70^{\mathrm{b}} \pm 0.10$ & $2.70^{\mathrm{b}} \pm 0.11$ & $2.72^{\mathrm{b}} \pm 0.11$ & $2.72^{\mathrm{ab}} \pm 0.11$ & $2.72^{\mathrm{ab}} \pm 0.11$ & $2.74^{\mathrm{ab}} \pm 0.10$ \\
\hline Shelf life (h) & $142^{\mathrm{a}} \pm 12.05$ & $133^{b} \pm 9.67$ & $137^{b} \pm 8.83$ & $134^{\mathrm{b}} \pm 10.21$ & $139^{b} \pm 11.64$ & $138^{\mathrm{b}} \pm 11.41$ & $138^{b} \pm 9.16$ \\
\hline
\end{tabular}

Pse: Pseudomonas spp.; DL: drip loss; CL: cooking loss; DLM: DL-methionine; DL-HMTBA: DL-methionine hydroxy analogue free acid.

TABLE 3: Spearman's $\rho$ correlation indices and p-values of meat quality parameters $24 \mathrm{~h}$ after slaughter.

\begin{tabular}{|c|c|c|c|c|c|c|c|c|c|c|c|}
\hline & Met conc. & Weight & Pse & $\mathrm{pH}$ & $\begin{array}{l}\text { Drip } \\
\text { loss }\end{array}$ & $\begin{array}{c}\text { Cooking } \\
\text { loss }\end{array}$ & $L^{*}$ & $a^{*}$ & $b^{*}$ & SI & Shelf life \\
\hline \multirow{2}{*}{ Weight } & $0.914^{* *}$ & & & & & & & & & & \\
\hline & 0.000 & & & & & & & & & & \\
\hline \multirow{2}{*}{ Pse } & 0.051 & .012 & & & & & & & & & \\
\hline & 0.609 & .906 & & & & & & & & & \\
\hline \multirow{2}{*}{$\mathrm{pH}$} & $0.176^{*}$ & $0.267^{* *}$ & 0.103 & & & & & & & & \\
\hline & 0.011 & 0.000 & 0.301 & & & & & & & & \\
\hline \multirow{2}{*}{ Drip loss } & $-0.205^{* *}$ & $-0.257^{* *}$ & -0.036 & $-0.209^{* *}$ & & & & & & & \\
\hline & 0.003 & 0.000 & 0.719 & 0.002 & & & & & & & \\
\hline \multirow{2}{*}{ Cooking loss } & $-0.377^{* *}$ & $-0.359^{* *}$ & 0.115 & $-0.214^{*}$ & $0.232^{*}$ & & & & & & \\
\hline & 0.000 & 0.000 & 0.257 & 0.029 & 0.018 & & & & & & \\
\hline \multirow{2}{*}{$L^{*}$} & $-0.250^{* *}$ & $-0.239^{* *}$ & -0.134 & $-0.308^{* *}$ & $0.260^{* *}$ & $0.357^{* *}$ & & & & & \\
\hline & 0.000 & 0.000 & 0.180 & 0.000 & 0.000 & 0.000 & & & & & \\
\hline \multirow{2}{*}{$a^{*}$} & $-0.246^{* *}$ & $-0.143^{*}$ & 0.019 & -0.114 & 0.072 & 0.107 & -0.104 & & & & \\
\hline & 0.000 & 0.038 & 0.852 & 0.099 & 0.302 & 0.279 & 0.132 & & & & \\
\hline \multirow{2}{*}{$b^{*}$} & -0.085 & -0.039 & 0.011 & $-0.187^{* *}$ & 0.127 & 0.079 & $0.533^{* *}$ & $0.318^{* *}$ & & & \\
\hline & 0.220 & 0.575 & 0.910 & 0.007 & 0.066 & 0.424 & 0.000 & 0.000 & & & \\
\hline Sensory & $-0.147^{* *}$ & $-0.158^{*}$ & -0.087 & -0.018 & -0.078 & 0.029 & $-0.346^{* *}$ & -0.001 & $-0.443^{* *}$ & & \\
\hline Index & 0.034 & 0.022 & 0.384 & 0.794 & 0.261 & 0.770 & 0.000 & 0.991 & 0.000 & & \\
\hline \multirow{2}{*}{ Shelf life } & -0.094 & -0.042 & $-0.196^{*}$ & $0.151^{*}$ & -0.084 & $-0.217^{*}$ & $-0.447^{* *}$ & 0.038 & $-0.380^{* *}$ & $0.579^{* *}$ & \\
\hline & 0.174 & 0.546 & 0.049 & 0.029 & 0.228 & 0.027 & 0.000 & 0.581 & 0.000 & 0.000 & \\
\hline \multirow{2}{*}{ WS } & $0.159^{*}$ & $0.207^{* *}$ & -0.116 & $0.194^{* *}$ & -0.036 & -0.087 & $0.354^{* *}$ & 0.131 & $0.343^{* *}$ & $-0.442^{* *}$ & $-0.364^{* *}$ \\
\hline & 0.021 & 0.003 & 0.244 & 0.005 & 0.609 & 0.381 & 0.000 & 0.058 & 0.000 & 0.000 & 0.000 \\
\hline
\end{tabular}

capacity by lowering drip loss and cooking loss values, independent of the Met source supplemented. Nevertheless, the information on the effect of Met supplementation on water-binding capacity of meat is inconsistent, and further research is needed to clarify the relationship. 
The data of the color measurement showed a high variation and broad overlap between groups (Figure 2). In general, increasing Met concentration led to lower $L^{*}$ values, lower $a^{*}$ values, and higher $b^{*}$ values, meaning that the fillets appear darker, with a lesser red and higher yellow portion. Mean $L^{*}$ values ranged between 55.68 and 58.8 at the first investigation point at $24 \mathrm{~h}$ (Table 2 ). $L^{*}$ values showed a significant decline during storage $(p<0.01)$. Samples showed significant differences in the $L^{*}$ value between the highest Met concentration and the lowest as well as medium concentration $(p<0.05)$. The color measurements conducted in this study revealed that poultry fillets were generally lighter in comparison to the optimal color for poultry fillets stated in former studies. In general, optimal $L^{*}$ values for poultry are given as $47 \leq L^{*} \leq 53$, taking into account the factors affecting meat color such as animal and process specific factors [49, 55-57]. Normally, higher $L^{*}$ values, above 56 [55] or 59 [49], are judged as pale, soft, and exudative (PSE) meat. But, since the samples investigated in this study expressed high $\mathrm{pH}$ values and a high waterbinding capacity, the meat cannot be judged as PSE meat. The broad occurrence of WS in the current study can be an explanation for high $L^{*}$ values, since $L^{*}$ values are significantly correlated to WS $(k: 0.354 ; p<0.001)$. Additionally, the color of meat is strongly influenced by genetic selection, slaughtering conditions, and diet, which might be a further reason for higher $L^{*}$ values [58-61].

The $a^{*}$ values ranged from 6.61 to 7.20 between all treatment groups at the beginning of storage (Table 2). There was no change observed for the $a^{*}$ values during storage. No significant differences between the Met sources could be observed, but the basal group showed significantly higher values than the $0.32 \%$ DL-HMTBA groups $(p<0.024)$. Additionally, $a^{*}$ values showed a significant negative correlation to the Met concentration as well as the $L^{*}$ values, but the effect was only observed at the first investigation point at $24 \mathrm{~h}$. The mean $b^{*}$ values ranged between 14.87 and 15.88 at the beginning of storage. There was a significant negative correlation to the Met concentration with the highest $b^{*}$ values measured at the lowest supplementation levels. Therefore, higher Met concentrations led to lower $L^{*}$ and $a^{*}$ values and higher $b^{*}$ values. Lower $L^{*}$ values under the effect of Met supplementation have been reported before [21, 29], but the results of $a^{*}$ and $b^{*}$ values contradict the findings of Liu et al. [62] who reported a "superior meat color."

The initial bacterial contamination of the samples showed mean values between $1.61 \log _{10} \mathrm{cfu} / \mathrm{g}$ and $2.17 \log _{10} \mathrm{cfu} / \mathrm{g}$ (Table 2). For industrial slaughter, these microbial loads are low in comparison to other studies, which reported mean bacteria numbers of $2.9 \log _{10} \mathrm{cfu} / \mathrm{cm}^{2}$ [63], $3.7 \log _{10} \mathrm{cfu} / \mathrm{g}$ [64], $3.8 \log _{10} \mathrm{cfu} / \mathrm{g}$ [65], and $4.1 \log _{10} \mathrm{cfu} / \mathrm{g}$ [27] after slaughter. However, the initial count of industrially slaughtered poultry can vary depending on slaughter and hygienic conditions during processing [66]. There was no difference in initial bacterial count between the different treatment groups ( $p>0.05)$ after $24 \mathrm{~h}$, indicating that all samples showed a comparable initial contamination by microorganisms. After $192 \mathrm{~h}$ storage, the mean microbial counts of Pseudomonas spp. ranged between $7.82 \log _{10} \mathrm{cfu} / \mathrm{g}$ and $8.51 \log _{10} \mathrm{cfu} / \mathrm{g}$
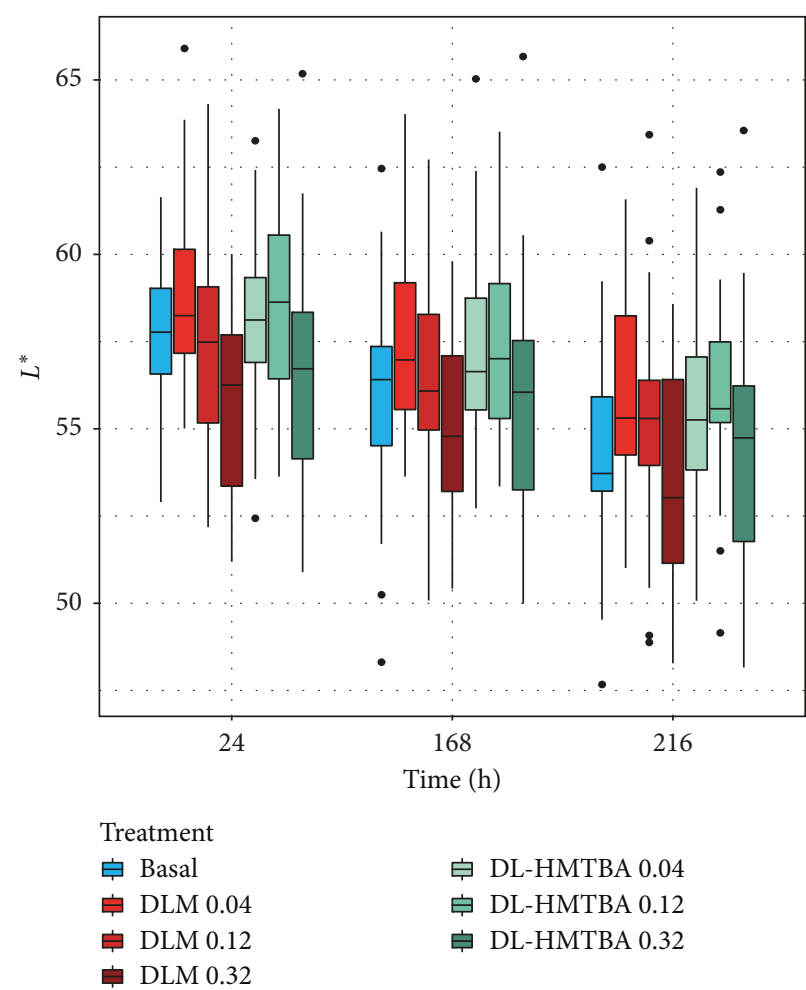

FIgURE 2: $L^{*}$ values of breast fillets during storage $(n=209)$.

(Table 2). The microbial acceptance level of Pseudomonas spp. is $7.5 \log _{10} \mathrm{cfu} / \mathrm{g}$ [27], which was exceeded by $88 \%$ of the samples. Pseudomonas spp. counts were negatively correlated to DLM concentration $(k:-0.339, p=0.001)$. This is contradictory to findings of our former study where results pointed to a positive correlation between Met concentration and microbial counts, irrespective of the Met source [24]. An effect of Met on lowering the bacterial counts on meat was also reported in [21], but no particular explanation was given. Since the relationship between Met supplementation and the growth of Pseudomonas spp. could not be clarified, further studies are needed to investigate if these effects are a result of causal connections or a statistical bias.

The sensory investigations revealed that the samples showed a normal initial meat quality upon arrival at the laboratory. The mean SI ranged between 2.7 and 2.8, $24 \mathrm{~h}$ after slaughter. The SI was evaluated significantly worse for the DLM and DL-HMTBA groups than for the basal group at the beginning of storage (Table 2), which is mainly caused by differences in the color evaluation. Additionally, a lownegative correlation between the SI and the Met concentration was detected $(k=-0.147 ; p=0.034)$. The SI showed a linear decline with time with a similar gradient for all treatment groups, meaning a similar speed of the spoilage process for all fillets. The mean sensory shelf life of the treatment groups ranged between $133 \mathrm{~h}$ and $142 \mathrm{~h}$ (Table 2). For commercially produced poultry, a shelf life of 6 days has been reported before [27]. The shelf life in the present study showed a significant difference between the DLM and the basal group $(p=0.01)$, but the difference is below $24 \mathrm{~h}$ and thus judged not relevant for the poultry industry. For SI and 
shelf life, there were no significant differences detected between the DLM and the DL-HMTBA group.

The evaluation of the Purchase Decision revealed significant differences between the treatment groups. The basal group was evaluated significantly better at all investigation points $(p<0.05)$. Linear modelling revealed that the parameters WS and color (visual assessment) had a significant influence on the Purchase Decision in the first $72 \mathrm{~h}$ of storage. In contrast, Met source or size of the fillets had no influence on the Purchase Decision (supplementary material, Tables 4 and 5). WS is supposed to affect the consumer acceptance of raw meat [34,67]. The relationship between color, WS, and Purchase Decision is shown in Figure 3. At the investigation points $24 \mathrm{~h}$ and $72 \mathrm{~h}$, the best Purchase Decision was achieved for fillets with the highest color scores and low scores for WS. WS led to less positive Purchase Decisions, even if the color of the fillets was optimal. As a consequence, fillets with a low rating for color and higher occurrence of WS were rejected by the sensory panel even if the spoilage level was not yet reached. With proceeding storage, the spoilage process became apparent and led to low ratings for Purchase Decision. Over $90 \%$ of all samples were rejected at $168 \mathrm{~h}$ when the meat was spoiled.

WS occurred in most of the samples with dominance on "medium WS" (Figure 4). For both Met sources, less than $10 \%$ of fillets were rated with "no WS." In contrast, over 30\% of the fillets of the basal group showed "no WS," which could be due to suboptimal Met supplementation below typical industrial conditions and lower growth rate.

The occurrence or severity of WS is weakly correlated with the concentration of Met supplementation $(k=0.159$; $p=0.021)$ and had a negative influence on the Purchase Decision. The correlation is weak, because severe WS was most distinct in the medium Met concentration. There was no significant difference in the severity of WS between the DLM and the DL-HMBTA groups. However, both Met groups expressed significantly more WS than the basal group. WS is a breast myopathy probably caused by the increased growth rate of animals in the modern poultry industry [31,33]. One-sided genetic selection for higher growth rates and meat yield has been linked to muscle abnormalities in earlier studies [37]. Even if several investigations could not relate genetic selection of commercial broiler lines to a negative impact on meat quality $[48,59]$, WS was observed significantly more often in heavier and fast-growing birds of modern broiler lines $[31,32,36,68]$. The dietary supplementation of lysine is reported to have an influence on protein metabolism and induces the occurrence of WS [69]. In addition to nutritional factors, a connection to changed metabolic mechanisms, proliferation of connective tissues, genetic predisposition, or a combination of these parameters, are discussed [70]. The detailed mechanisms causing WS are still not clear [34]. Thus, the nature of the effect of Met supplementation on the occurrence of WS, whether it is causal or rather a side effect, and its interaction with other factors are currently unclear. Further investigations are needed to clarify these effects.

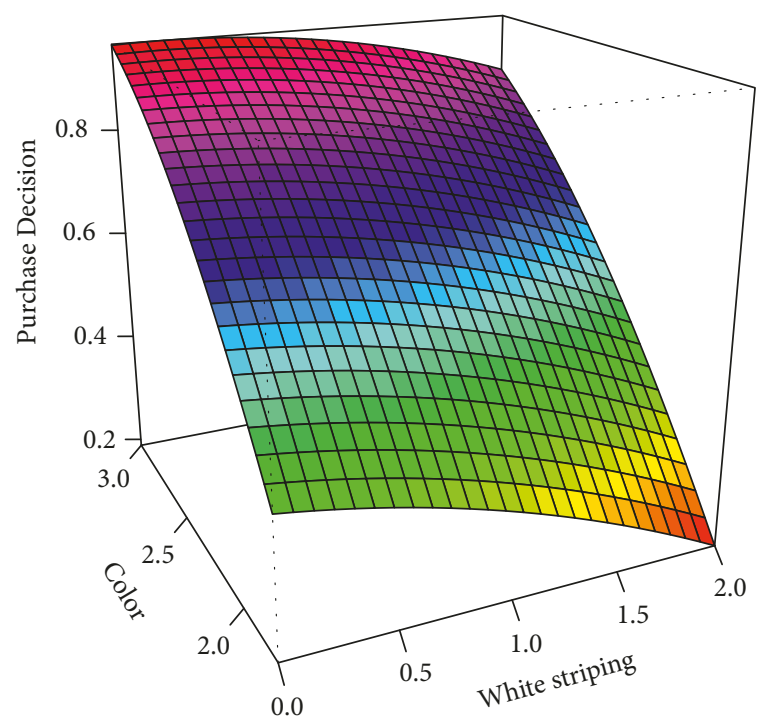

FIgURe 3: Influence of color and WS on the Purchase Decision $(t=24 \mathrm{~h}$ and $72 \mathrm{~h})$.

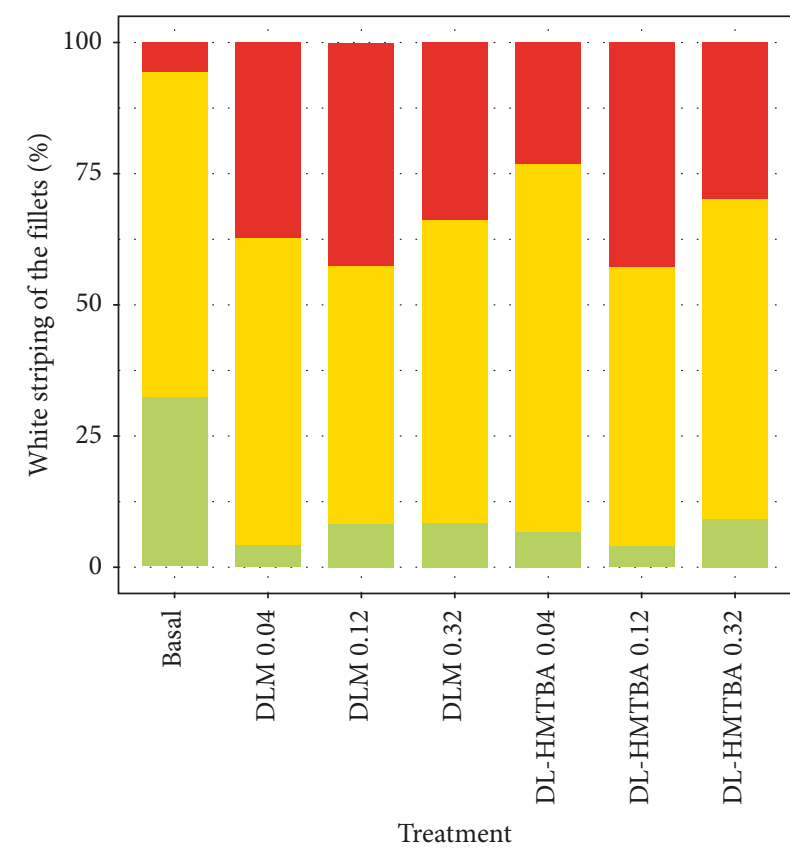

White striping

No WS

Medium WS

Severe WS

FIGURE 4: Occurrence of WS in breast fillets.

\section{Conclusions}

The supplementation of Met at three different dietary levels showed a significant effect on the meat yield and quality of broiler fillets in comparison to the basal group. Met supplementation resulted in higher $\mathrm{pH}$ values and showed a positive effect on water-binding capacity, irrespective of the Met source used. The microbial load at the end of storage decreased with increasing Met concentration, but this effect 
did not lead to a relevant prolongation of shelf life. The shelf life of the fillets was 6 days, which is a proper shelf life for industrially produced, aerobically stored poultry fillets. Met supplementation was negatively correlated to $L^{*}, a^{*}$, and $b^{*}$ measurements, to a magnitude that was also visually noticed by the sensory panel. WS occurred in most of the samples and was significantly correlated to fillet weight. The occurrence of WS showed a low correlation to Met concentration and significantly affected the color of the samples as well as Purchase Decision. No specific parameter provoking WS could be identified. In summary, the effects of dietary Met supplementation on the quality and freshness of poultry meat is complex, and more research is needed to clarify the relationship between dietary Met supplementations and meat quality as well as the occurrence of WS.

\section{Data Availability}

The data supporting the findings of this study are available at the Institute of Animal Science, University of Bonn, Germany.

\section{Conflicts of Interest}

The authors state that there are no conflicts of interest.

\section{Acknowledgments}

The authors thank Hannelore Brüssel, Deborah Elsler, Carina Braun, Sophia Dohlen, Dilek Eren, Nicola Kolmar, and Alisa Schaefer for supporting the study during the laboratory work.

\section{Supplementary Materials}

Linear modelling (forward stepwise) for assessing the influence of the predictors on the Purchase Decision (AICC: $\left.-1,508.295, R^{2}=0.724\right)$. Table 4 : model summary effects: target variable-Purchase Decision. Table 5: model summary coefficients: target variable-Purchase Decision. Table 6: meat quality parameters at the end of shelf life. (Supplementary Materials)

\section{References}

[1] C. Bunchasak, "Role of dietary methionine in poultry production," Journal of Poultry Science, vol. 46, no. 3, pp. 169179, 2009.

[2] D. H. Baker, "Comparative species utilization and toxicity of sulfur amino acids," Journal of Nutrition, vol. 136, no. 6, pp. 1670S-1675S, 2006.

[3] I. R. Wallis, "Dietary supplements of methionine increase breast meat yield and decrease abdominal fat in growing broiler chickens," Australian Journal of Experimental Agriculture, vol. 39, no. 2, p. 131, 1999.

[4] J. D. Garlich, "Response of broilers to DL-methionine hydroxy analog free acid, DL-methionine, and L-methionine," Poultry Science, vol. 64, no. 8, pp. 1541-1548, 1985.

[5] C. P. Sangali, L. D. G. Bruno, R. V. Nunes et al., "Bioavailability of different methionine sources for broilers from 1 to 21 days old," Ciencia e Investigación Agraria, vol. 42, no. 1, pp. 7-8, 2015.
[6] D. Vedenov and G. M. Pesti, "An economic analysis of a methionine source comparison response model," Poultry Science, vol. 89, no. 11, pp. 2514-2520, 2010.

[7] N. Sauer, K. Emrich, H.-P. Piepho, A. Lemme, M. S. Redshaw, and R. Mosenthin, "Meta-analysis of the relative efficiency of methionine-hydroxy-analogue-free-acid compared with DLmethionine in broilers using nonlinear mixed models," Poultry Science, vol. 87, no. 10, pp. 2023-2031, 2008.

[8] C. Elwert, E. D. A. Fernandes, and A. Lemme, "Biological effectiveness of methionine hydroxy-analogue calcium salt in relation to DL-methionine in broiler chickens," AsianAustralasian Journal of Animal Sciences, vol. 21, no. 10, pp. 1506-1515, 2008.

[9] M. Vazquez-AnOn, D. Kratzer, R. Gonzalez-Esquerra, I. G. Yi, and C. D. Knight, "A multiple regression model approach to contrast the performance of 2-hydroxy-4methylthio butanoic acid and DL-methionine supplementation tested in broiler experiments and reported in the literature," Poultry Science, vol. 85, no. 4, pp. 693-705, 2006.

[10] D. Hoehler, A. Lemme, S. K. Jensen, and S. L. Vieira, "Relative effectiveness of methionine sources in diets for broiler chickens," Journal of Applied Poultry Research, vol. 14, no. 4, pp. 679-693, 2005.

[11] A. B. Vieira, A. V. Elangovan, and T. S. Johri, "Comparing bio-efficacy of liquid DL-methionine hydroxy analogue free acid with DL-methionine in broiler chickens," AsianAustralasian Journal of Animal Sciences, vol. 17, no. 1, pp. 102-108, 2004.

[12] H. T. Meirelles, R. Albuquerque, L. M. O. Borgatti, L. W. O. Souza, N. C. Meister, and F. R. Lima, "Performance of broilers fed with different levels of methionine hydroxy analogue and DL-methionine," Revista Brasileira de Ciência Avícola, vol. 5, no. 1, pp. 69-74, 2003.

[13] G. Huyghebaert, "Comparison of DL-methionine and methionine hydroxy analogue-free acid in broilers by using multi-exponential regression models," British poultry science, vol. 34, no. 2, pp. 351-359, 1993.

[14] S. Zhang, B. Saremi, E. R. Gilbert, and E. A. Wong, "Physiological and biochemical aspects of methionine isomers and a methionine analogue in broilers," Poultry Science, vol. 96, no. 2, pp. 425-439, 2016.

[15] J. D. Wong, C. A. Atwell, M. Vazquez-Anon, and J. J. Dibner, "Comparative in vitro and in vivo absorption of 2-hydroxy-4(methylthio) butanoic acid and methionine in the broiler chicken," Poultry Science, vol. 84, no. 9, pp. 1397-1405, 2005.

[16] X. A. Dibner, J. X. Li, Z. R. Xu, and R. Q. Zhao, "Effects of methionine and betaine supplementation on growth performance, carcase composition and metabolism of lipids in male broilers," British poultry science, vol. 47, no. 5, pp. 576-580, 2007.

[17] J. H. Yao, S. Q. Li, L. L. Zhong, S. X. Huang, W. J. Zhang, and H. B. Xi, "The relative effectiveness of liquid methionine hydroxy analogue compared to DL-methionine in broilers," Asian-Australasian Journal of Animal Sciences, vol. 19, no. 7, pp. 1026-1032, 2006.

[18] Y. L. Liu, G. L. Song, G. F. Yi et al., "Effect of supplementing 2hydroxy-4-(methylthio) butanoic acid and DL-methionine in corn-soybean-cottonseed meal diets on growth performance and carcass quality of broilers," Asian-Australasian Journal of Animal Sciences, vol. 19, no. 8, pp. 1197-1205, 2006.

[19] M. A. Motl, C. A. Fritts, and P. W. Waldroup, "Influence of dietary sodium level on utilization of methionine from 
DL-methionine and liquid methionine-hydroxy analogue1," Journal of Applied Poultry Research, vol. 14, no. 1, pp. 147-155, 2005.

[20] E. Daenner and W. Bessei, "Influence of supplementation with liquid DL-methionine hydroxy analogue-free acid (alimet) or DL-methionine on performance of broilers," Journal of Applied Poultry Research, vol. 12, no. 2, pp. 101-105, 2003.

[21] M. İ. Aksu, H. İmik, and M. Karaoğlu, "Influence of dietary sorghum (sorghum vulgare) and corn supplemented with methionine on cut-up pieces weights of broiler carcass and quality properties of breast and drumsticks meat," Food Science and Technology International, vol. 13, no. 5, pp. 361-367, 2016.

[22] A. M. Fouad and H. K. El-Senousey, "Nutritional factors affecting abdominal fat deposition in poultry: a review," Asian-Australasian Journal of Animal Sciences, vol. 27, no. 7, pp. 1057-1068, 2014.

[23] K. Takahashi and Y. Akiba, "Effect of methionine supplementation on lipogenesis and lipolysis in broiler chicks," Japanese Poultry Science, vol. 32, no. 2, pp. 99-106, 1995.

[24] A. Albrecht, U. Herbert, D. Miskel et al., "Effect of methionine supplementation in chicken feed on the quality and shelf life of fresh poultry meat," Poultry Science, vol. 96, no. 8, pp. 2853-2861, 2017.

[25] J. H. J. Huis in't Veld, "Microbial and biochemical spoilage of foods: an overview," International Journal of Food Microbiology, vol. 33, no. 1, pp. 1-18, 1996.

[26] C. O. Gill, "Meat spoilage and evaluation of the potential storage life of fresh meat," Journal of Food Protection, vol. 46, no. 5, pp. 444-452, 1983.

[27] S. Bruckner, A. Albrecht, B. Petersen, and J. Kreyenschmidt, "Characterization and comparison of spoilage processes in fresh pork and poultry," Journal of Food Quality, vol. 35, no. 5, pp. 372-382, 2012.

[28] C. Berri, S. Métayer-Coustard, A.-P. Geraert et al., "Effect of 3 methionine sources and levels on broiler meat quality," in Proceedings of World's Poultry Congress, Bahia, Brazil, August 2012.

[29] Z. G. Kreyenschmidt, X. J. Pan, Z. Q. Peng, R. Q. Zhao, and G. H. Zhou, "Methionine and selenium yeast supplementation of the maternal diets affects color, water-holding capacity, and oxidative stability of their male offspring meat at the early stage," Poultry Science, vol. 88, no. 5, pp. 1096-1101, 2009.

[30] D. Ladikos and V. Lougovois, "Lipid oxidation in muscle foods: a review," Food Chemistry, vol. 35, no. 4, pp. 295-314, 1990.

[31] M. Petracci, S. Mudalal, F. Soglia et al., "Meat quality in fastgrowing broiler chickens," World's Poultry Science Journal, vol. 71, no. 2, pp. 363-374, 2015.

[32] V. A. Kuttappan, V. B. Brewer, A. Mauromoustakos et al., "Estimation of factors associated with the occurrence of white striping in broiler breast fillets," Poultry Science, vol. 92, no. 3, pp. 811-819, 2013.

[33] V. A. Kuttappan, V. B. Brewer, J. K. Apple, P. W. Waldroup, and C. M. Owens, "Influence of growth rate on the occurrence of white striping in broiler breast fillets," Poultry Science, vol. 91, no. 10, pp. 2677-2685, 2012.

[34] V. A. Kuttappan, B. M. Hargis, and C. M. Owens, "White striping and woody breast myopathies in the modern poultry industry: a review," Poultry Science, vol. 95, no. 11, pp. 2724-2733, 2016.

[35] S. Mudalal, M. Lorenzi, F. Soglia, C. Cavani, and M. Petracci, "Implications of white striping and wooden breast abnormalities on quality traits of raw and marinated chicken meat," Animal: An International Journal of Animal Bioscience, vol. 9, no. 4, pp. 728-734, 2015.
[36] M. Petracci, S. Mudalal, A. Bonfiglio, and C. Cavani, "Occurrence of white striping under commercial conditions and its impact on breast meat quality in broiler chickens," Poultry Science, vol. 92, no. 6, pp. 1670-1675, 2013.

[37] E. Dransfield and A. Sosnicki, "Relationship between muscle growth and poultry meat quality," Poultry Science, vol. 78, no. 5, pp. 743-746, 1999.

[38] G. R. Trout, "Techniques for measuring water-binding capacity in muscle foods-a review of methodology," Meat science, vol. 23, no. 4, pp. 235-252, 1988.

[39] J. Kreyenschmidt, Modellierung des Frischeverlustes von Fleisch sowie des Entfärbeprozesses von Temperatur-ZeitIntegratoren zur Festlegung von Anforderungsprofilen für die produktbegleitende Temperaturüberwachung, Agrimedia, Bergen, Norway, 2003.

[40] R. G. Garcia, L. d. Freitas, A. W. Schwingel et al., "Incidence and physical properties of PSE chicken meat in a commercial processing plant," Revista Brasileira de Ciência Avícola, vol. 12, no. 4, pp. 233-237, 2010.

[41] M. Debut, C. Berri, E. Baeza et al., "Variation of chicken technological meat quality in relation to genotype and preslaughter stress conditions," Poultry Science, vol. 82, no. 12, pp. 1829-1838, 2003.

[42] G.-J. E. Nychas, P. N. Skandamis, C. C. Tassou, and K. P. Koutsoumanis, "Meat spoilage during distribution," Meat science, vol. 78, no. 1-2, pp. 77-89, 2008.

[43] A. P. Del Vesco, E. Gasparino, A. R. Oliveira Neto, R. M. Rossi, M. A. Menck Soares, and S. C. Claudino da Silva, "Effect of methionine supplementation on mitochondrial genes expression in the breast muscle and liver of broilers," Livestock Science, vol. 151, no. 2-3, pp. 284-291, 2013.

[44] S. Luo and R. L. Levine, "Methionine in proteins defends against oxidative stress," FASEB Journal, vol. 23, no. 2, pp. 464-472, 2009.

[45] Y.-Z. Fang, S. Yang, and G. Wu, "Free radicals, antioxidants, and nutrition," Nutrition, vol. 18, no. 10, pp. 872-879, 2002.

[46] C. Berri, "Variability of sensory and processing qualities of poultry meat," World's Poultry Science Journal, vol. 56, no. 3, pp. 209-224, 2000.

[47] E. Huff-Lonergan and S. M. Lonergan, "Mechanisms of waterholding capacity of meat: the role of postmortem biochemical and structural changes," Meat science, vol. 71, no. 1, pp. 194-204, 2005.

[48] E. Le Bihan-Duval, M. Debut, C. M. Berri et al., "Chicken meat quality: genetic variability and relationship with growth and muscle characteristics," BMC genetics, vol. 9, no. 1, p. 53, 2008.

[49] R. L. Woelfel, C. M. Owens, E. M. Hirschler, R. MartinezDawson, and A. R. Sams, "The characterization and incidence of pale, soft, and exudative broiler meat in a commercial processing plant," Poultry Science, vol. 81, no. 4, pp. 579-584, 2002.

[50] R. van Laack, C.-H. Liu, M. O. Smith, and H. D. Loveday, "Characteristics of pale, soft, exudative broiler breast meat," Poultry Science, vol. 79, no. 7, pp. 1057-1061, 2000.

[51] Z. Jiang, Y. Lin, G. Zhou, L. Luo, S. Jiang, and F. Chen, "Effects of dietary selenomethionine supplementation on growth performance, meat quality and antioxidant property in yellow broilers," Journal of agricultural and food chemistry, vol. 57, no. 20, pp. 9769-9772, 2009.

[52] C. Berri, J. Besnard, and C. Relandeau, "Increasing dietary lysine increases final $\mathrm{pH}$ and decreases drip loss of broiler breast meat," Poultry Science, vol. 87, no. 3, pp. 480-484, 2008.

[53] J. F. Young, A. H. Karlsson, and P. Henckel, "Water-holding capacity in chicken breast muscle is enhanced by pyruvate and 
reduced by creatine supplements," Poultry Science, vol. 83, no. 3, pp. 400-405, 2004.

[54] K. M. Downs, J. B. Hess, and S. F. Bilgili, "Selenium source effect on broiler carcass characteristics, meat quality and drip loss," Journal of Applied Animal Research, vol. 18, no. 1, pp. 61-71, 2000.

[55] M. Petracci, M. Betti, M. Bianchi, and C. Cavani, "Color variation and characterization of broiler breast meat during processing in Italy," Poultry Science, vol. 83, no. 12, pp. 2086-2092, 2004.

[56] C. D. Allen, D. L. Fletcher, J. K. Northcutt, and S. M. Russell, "The relationship of broiler breast color to meat quality and shelf-life," Poultry Science, vol. 77, no. 2, pp. 361-366, 1998.

[57] S. Barbut, "Problem of pale soft exudative meat in broiler chickens," British Poultry Science, vol. 38, no. 4, pp. 355-358, 1997.

[58] D. L. Fletcher, "Poultry meat quality," World's Poultry Science Journal, vol. 58, no. 2, pp. 131-145, 2002.

[59] C. Berri, N. Wacrenier, N. Millet, and E. Le Bihan-Duval, "Effect of selection for improved body composition on muscle and meat characteristics of broilers from experimental and commercial lines," Poultry Science, vol. 80, no. 7, pp. 833-838, 2001.

[60] G. W. Froning, "Color of poultry meat," Poultry and Avian Biology Reviews, vol. 6, no. 1, pp. 83-93, 1995.

[61] D. J. Mugler and F. E. Cunningham, "Factors affecting poultry meat color-a review," World's Poultry Science Journal, vol. 28, no. 4, pp. 400-406, 1972.

[62] F. Liu, R.-Q. Yang, and Y.-f. Li, "Correlations between growth parameters of spoilage micro-organisms and shelf-life of pork stored under air and modified atmosphere at $-2,4$ and $10^{\circ} \mathrm{C}$," Food Microbiology, vol. 23, no. 6, pp. 578-583, 2006.

[63] A. Sahar and É. Dufour, "Use of Fourier transform-infrared spectroscopy to predict spoilage bacteria on aerobically stored chicken breast fillets," LWT-Food Science and Technology, vol. 56, no. 2, pp. 315-320, 2014.

[64] V. Raab, S. Bruckner, E. Beierle, Y. Kampmann, B. Petersen, and J. Kreyenschmidt, "Generic model for the prediction of remaining shelf life in support of cold chain management in pork and poultry supply chains," Journal on Chain and Network Science, vol. 8, no. 1, pp. 59-73, 2008.

[65] H. Vasconcelos, C. Saraiva, and J. M. M. M. de Almeida, "Evaluation of the spoilage of raw chicken breast fillets using fourier transform infrared spectroscopy in tandem with chemometrics," Food and Bioprocess Technology, vol. 7, no. 8, pp. 2330-2341, 2014.

[66] J. F. R. Lues, M. M. Theron, P. Venter, and M. H. R. Rasephei, "Microbial composition in bioaerosols of a high-throughput chicken-slaughtering facility," Poultry Science, vol. 86, no. 1, pp. 142-149, 2007.

[67] G. Sanchez Brambila, B. C. Bowker, and H. Zhuang, "Comparison of sensory texture attributes of broiler breast fillets with different degrees of white striping," Poultry Science, vol. 95, no. 10, pp. 2472-2476, 2016.

[68] E. Russo, M. Drigo, C. Longoni, R. Pezzotti, P. Fasoli, and C. Recordati, "Evaluation of White Striping prevalence and predisposing factors in broilers at slaughter," Poultry Science, vol. 94, no. 8, pp. 1843-1848, 2015.

[69] R. F. A. Cruz, S. L. Vieira, L. Kindlein, M. Kipper, H. S. Cemin, and S. M. Rauber, "Occurrence of white striping and wooden breast in broilers fed grower and finisher diets with increasing lysine levels," Poultry Science, vol. 96, no. 2, pp. 501-510, 2017.

[70] G. Baldi, F. Soglia, M. Mazzoni et al., "Implications of white striping and spaghetti meat abnormalities on meat quality and histological features in broilers," Animal, vol. 12, no. 1, pp. 164-173, 2017. 


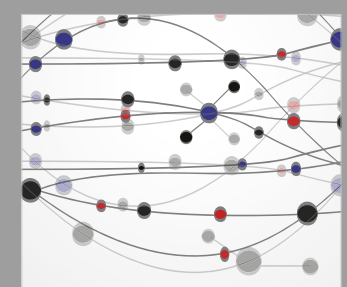

The Scientific World Journal
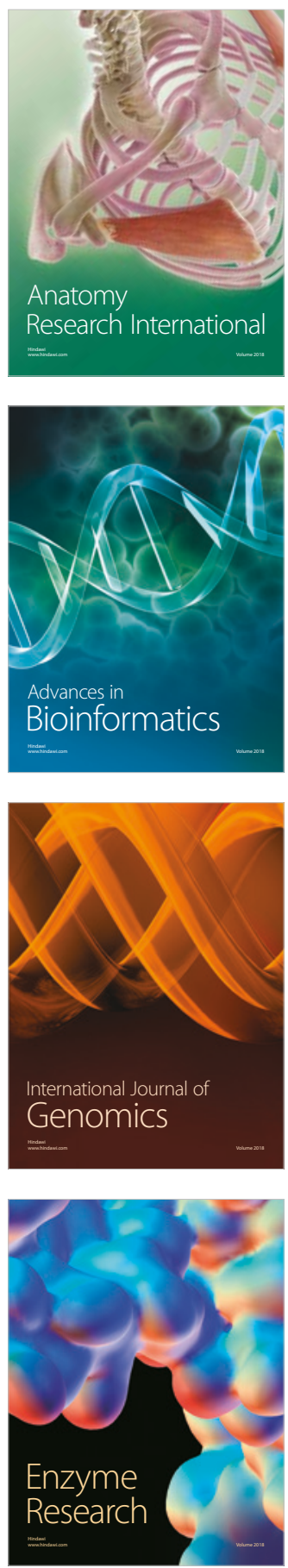
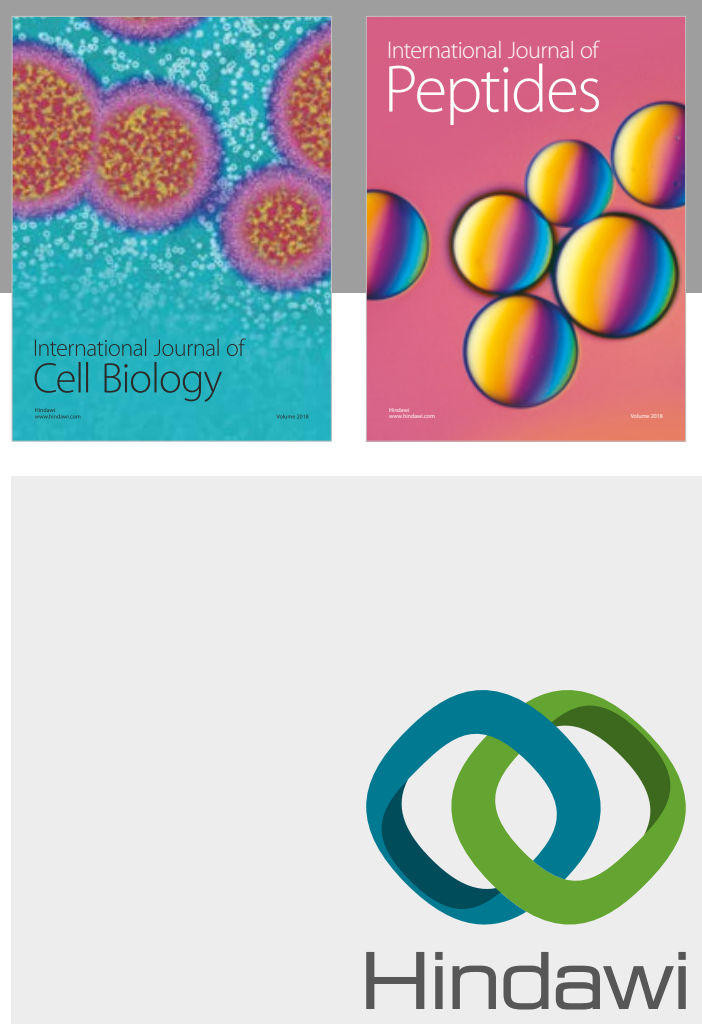

Submit your manuscripts at

www.hindawi.com
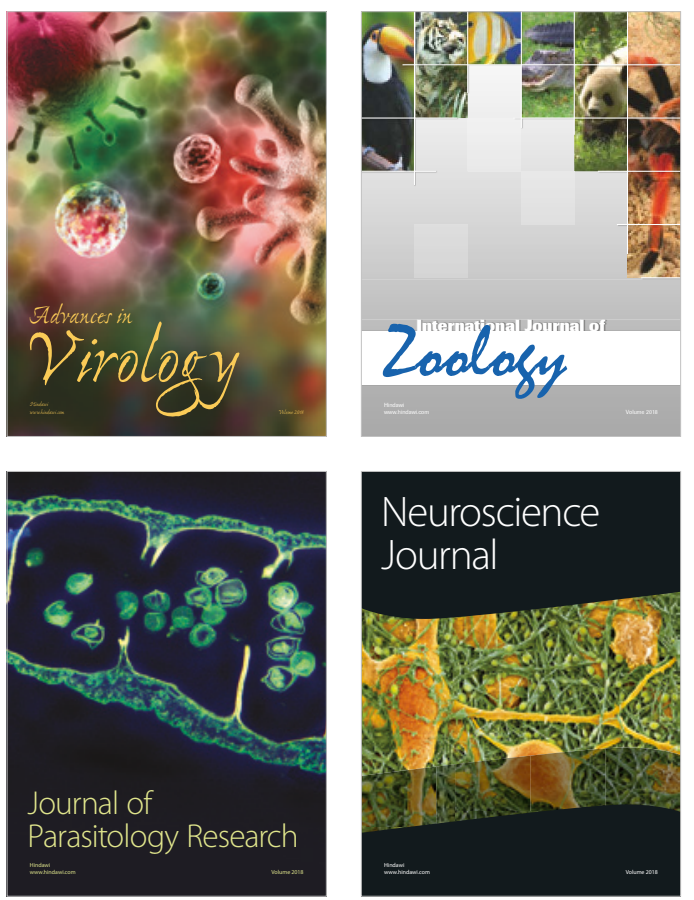
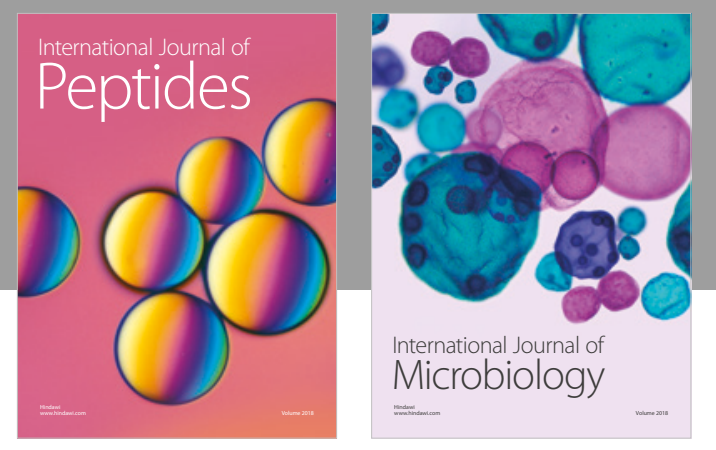

nternational Journal of Microbiology
Journal of
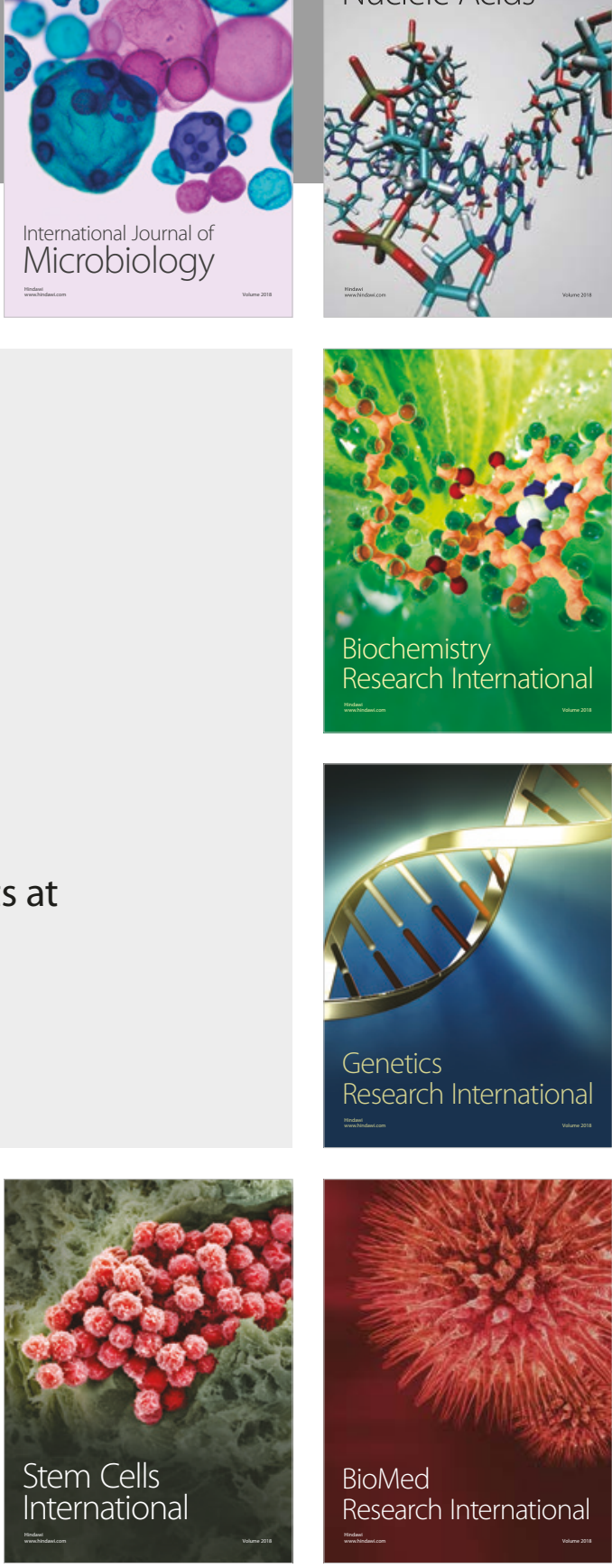
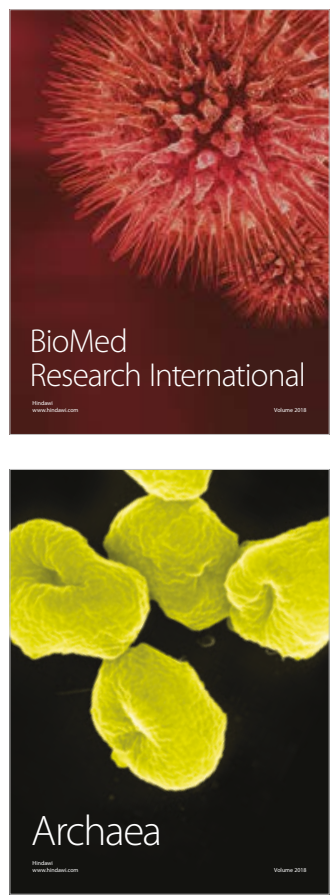